\title{
WALTER BENJAMIN Y GEORGES SOREL: ENTRE EL MITO DE LA HUELGA GENERAL Y UNA POLÍTICA DE MEDIOS PUROS
}

\author{
Carlos Pérez López ${ }^{l}$
}

\begin{abstract}
RESUMEN: En su ensayo Para una critica de la violencia, Walter Benjamin reivindica el fenómeno social de la huelga general revolucionaria teorizada por Georges Sorel en su obra Reflexiones sobre la violencia, como una figura ejemplar de lo que sería un "medio puro de la política", al margen de cualquier forma legitimada de poder. En este marco, pocos comentadores contemporáneos advierten una discordancia conceptual entre ambos filósofos: para Sorel, la huelga revolucionaria es un mito social, mientras que el mito, categoría esencialmente negativa en Benjamin, describe la violencia que aprisiona la vida y que se traduce en una forma de poder político superior. En este artículo quisiéramos demostrar esta discordancia conceptual para examinar en seguida cómo ha sido comentada por otros pensadores contemporáneos. La filosofía de la historia, la posibilidad de una acción política ética y la temporalidad mesiánica aparecen en el horizonte teórico que emparenta a estos filósofos y por el cual podría descifrarse su impasse conceptual. Esto se confirma si se despliega la idea de un "medio puro de la política”, pista que Benjamin ofrece sin profundizar y sobre la cual reenvía al pensamiento de un filósofo poco explorado, Erich Unger. En la última parte de este artículo desarrollaremos las claves dadas por Unger, que entran justamente en sintonía con la mención de la huelga general como medio puro de la política.
\end{abstract}

PALABRAS CLAVES: Walter Benjamin. Georges Sorel. Erich Unger. Huelga general. Mito.

\section{INTRODUCCIÓN}

Existe prácticamente un consenso en la comunidad científica conocedora de la obra de Walter Benjamin sobre algunas dificultades de interpretación de orden filosófico, político, teológico y sociológico presentes en su ensayo Para una critica de la violencia. Al respecto, las lecturas contemporáneas de filósofos que abordan este texto suelen atender a dos flancos: por una parte, a sus antecedentes biográficos e históricos enmarcados en la crisis política de Alemania en los años '20; por la otra, a las figuras teóricas y prácticas que generan su trama conceptual (dogma jurídico sobre

\footnotetext{
${ }^{1}$ Investigador del Instituto de Arte de la Pontificia Universidad Católica de Valparaíso, Chile. Investigador Postdoctoral Fondecyt-2015 (proyecto no 3150184), Facultad de Artes, Universidad de Chile. Doctor en Filosofía de la Universidad de Paris 8, Francia. Dirección: Las Madreselvas no 1010. Código postal: 8980235. Lo Prado. Santiago. Chile. Teléfono: 00.56.9.96329560. E-mail: zerepsolrac@gmail.com
} 
violencia y poder; relación entre moral y acción revolucionaria; un posible nuevo horizonte para la filosofía de la historia). Ciertamente, estas lecturas precisan una reconstrucción de sus argumentos y al hacerlo, definen puntos de convergencia o de divergencia que permiten sostener la orientación de este filósofo alemán en la gama problemática señalada.

Ante el gran número de textos que abordan directa o indirectamente Para una crítica de la violencia, limitaremos este artículo al estudio de un tema específico y singular ahí referido, el de la huelga general teorizada por Georges Sorel en su obra Reflexiones sobre la violencia (en adelante Reflexiones). En este contexto, intentaremos trabajar en particular un problema detectado en nuestra propia investigación sobre las lecturas contemporáneas del texto de Benjamin, pues entre los comentaristas de su ensayo pasa a menudo inadvertida una discordancia teórica en la referencia a Sorel, invocado por Benjamin para zanjar una ambivalencia en el fenómeno social de la "huelga general" (entre sus versiones política y revolucionaria), discordancia que se daría en la noción de "mito" usada por ambos autores.

Para exponer lo anterior, nuestro artículo se organiza en tres partes. En la primera quisiéramos introducir el problema tal cual se estaría presentando en la comparación de ambos filósofos, es decir en el uso que harían de un mismo concepto para describir realidades incompatibles. En la segunda parte, nos interesa desplegar el estado actual de las lecturas contemporáneas dedicadas al estudio de estos autores, entre las cuales se cuentan aquellas que identifican el problema, las que dan referencia al campo conceptual que lo teoriza y las que aportan hipótesis sobre la función del mito de Sorel en el pensamiento político de Benjamin. En la última parte abordaremos una vía alternativa de respuesta, a partir del propio Benjamin, sobre un autor citado en su ensayo en una nota a pie de página, precisamente en el pasaje que conduce al tema de la "huelga general". Se trata de la obra Politik und Metaphysik del filósofo alemán Erich Unger, referencia no traducida a otras lenguas, casi inexplorada en los estudios sobre el pensamiento político de Benjamin y teóricamente decisiva, a nuestro parecer, en lo que respecta al marco filosófico, político y ético sobre el que cabría pensar la figura ejemplar de la huelga general en el ensayo Para una crítica de la violencia. 


\section{El PROBLEMA: UN MISMO CONCEPTO PARA DOS REALIDADES INCOMPATIBLES}

Tal como aparece en Para una critica de la violencia, la noción de "mito" asociada a la política es radicalmente negativa (BENJAMIN, 2009, p. 443449). El tema central de su escrito es mostrar el modo en que la violencia del destino, de la venganza y de la culpabilidad, temática fundamental de los mitos griegos, se traduce históricamente en la instauración del derecho y en el poder que ejercen las formas jurídicas y las potencias políticas superiores (Estado) sobre la cotidianeidad de la vida humana ${ }^{2}$. En este sentido, el mito encuentra un camino por el cual se infiltra en la historia imponiendo un horizonte insuperable, llegando a invadir incluso aquellos conceptos fundamentales de la modernidad que supuestamente asegurarían una autonomía política y ética para la humanidad: libertad e igualdad (p. 433, 445). Ahora bien, el carácter aparentemente definitivo de esta clausura del tiempo histórico por el brazo mítico de la ley no es, según Benjamin, invulnerable. Existen medios creados por la humanidad cuya aplicación logra desarticular y aun destruir el imperio del derecho y de su violencia mítica sobre la vida. Benjamin los llama "medios puros". Se trata de acciones esencialmente no violentas que responden a conflictos entre sujetos. Estos medios abundan en el lenguaje y en la técnica (en su sentido más amplio, según indica el propio filósofo), como por ejemplo en el diálogo, en la cultura de la cordialidad o en la empatía. Incluso la mentira es citada por Benjamin como una técnica de comunicación no violenta y resolutiva, independientemente de las consecuencias perjudiciales que puedan generarse a partir de un conflicto dado (p. 438). No obstante, los medios puros no se limitan al ámbito privado de relaciones intersubjetivas conflictivas, superables mediante técnicas comunicativas o acuerdos de palabra. También existen los "medios puros de la política", pues la política es manifiestamente un lugar de conflictos y su aplicación, según Benjamin, sería análoga a la de los medios puros del lenguaje. Benjamin argumenta que cuando ya no son hombres, sino Estados los que entran en disputa, existe la diplomacia como medio puro con recursos que permiten evitar un desenlace bélico. La diplomacia genera un espacio de comunicación que a la vez puede ubicarse por encima del poder de las leyes o de cualquier instancia jurídica obligatoria, al tener la facultad de operar acuerdos haciendo caso omiso de un marco legal existente. Sin embargo, cuando se trata de conflictos entre clases, el diálogo entre pares superpuesto a la ley deja de ser un lugar resolutivo. No

\footnotetext{
${ }^{2}$ La distinción teológico-política ya bien conocida en Benjamin entre violencia mítica (fundadora y conservadora de derecho) y violencia divina (revolucionaria) es precisamente correlativa a esta situación de la vida humana supeditada a un orden superior y a las acciones que rompen con ese poder.
} 
por ello falta ahí un medio puro que lo asuma. Es ahí donde Benjamin invoca a Sorel y a su concepción "ingeniosa" de la huelga general proletaria, que sería la figura ejemplar del medio puro político decisivo en el conflicto histórico de la lucha de clases (p. 439-441).

Benjamin atribuye a Sorel el mérito de distinguir "por primera vez" entre dos especies de huelga general, una denominada "política", cuyo fundamento es lisa y llanamente el interés por el poder estatal; la otra, "revolucionaria", cuya praxis abiertamente anarquista, se propone la aniquilación de la violencia estatal, siendo ella misma una manifestación de la no-violencia (BENJAMIN, 2009, p. 440). En este plano, la virtud de Sorel no radica en haber expuesto una técnica huelguista inexistente hasta ese entonces, sino en haber encontrado un criterio para aquella distinción de huelgas, llamando la atención sobre el modo en que decanta históricamente el conflicto obrero en la lucha de clases anunciada por Marx. Arrastrada por más de un siglo, la lucha de clases llegó a un punto de saturación a fines del siglo XIX en Francia, en la formación del movimiento anarco-sindicalista y del sindicalismo revolucionario francés. Este movimiento social concibió y promovió la idea de la huelga general revolucionaria: suspender todo trabajo a la misma hora, a escala internacional. Pero más allá del carácter universal de su definición, lo teóricamente innovador en este movimiento fue el haber dado cuenta cabal de los sujetos que intervienen históricamente en este conflicto, cuestión que pasaba inadvertida en la mera oposición entre burguesía y proletariado en una lucha final. Y es que esta última representación no plantea el rol preponderante que intentan adquirir previamente las formas jurídicas (derecho a huelga y ley de sindicatos) y el Estado (mediador en el conflicto). La teoría de los sindicalistas, recuperada por Sorel en sus Reflexiones, capta y desarticula el ingreso del Estado y de los partidos políticos como actores válidos de la lucha de clases (SOREL, 1973, 119-154). En términos prácticos, los sindicalistas reivindicaban aquellas organizaciones sociales carentes de una figura autoritaria guía, representada en la figura de los intelectuales de partido (p. 141), anulando cualquier dinámica de toma de poder, produciendo a la vez un corto-circuito en la herencia de instituciones políticas de cualquier régimen anterior (p. 89-90). La destrucción del Estado, entendida a partir de la descripción histórica y teórica de este movimiento social, pasa por desmantelar antes que nada la ambición de regir el Estado, lo cual significa suprimir la intención de llegar a un mundo socialista dominando las instituciones que ejercen poder mediante el control de gobiernos y parlamentos o mediante reformas que conduzcan progresivamente a una emancipación de la humanidad y a una sociedad sin clases. En tal contexto reformista, el proletario no sería más que una masa electoral y la misma huelga 
general no pasaría de ser un mero medio "político" de extorsión (p. 155-186). Según Sorel, el modo de destruir esa intención ambiciosa e instrumental era la propagación simultánea de aquella otra idea universal al interior del movimiento social sindicalista en plena expansión: la idea revolucionaria de la huelga general, la idea de generar recursos durante un lapso determinado y de realizar en tiempo presente un ethos del trabajador como productor y un modo de vida indiferente al Estado y a las formas jurídicas. De esa manera, las ideas del sindicalismo revolucionario representan la concepción ingeniosa por la cual sería evacuada la violencia de la confrontación inmediatamente física contra fuerzas armadas, gracias al concepto revolucionario de la huelga general proletaria: negar el deseo por el poder político, generar un modo de vida moral del proletario, propagar la preparación del mundo por venir desde ya operativo en las organizaciones sindicalistas (p. 227-269) ${ }^{3}$.

Sin embargo, en este punto se produce un desajuste, o una suerte de contradicción entre Benjamin y Sorel. Y es que dicha concepción ingeniosa de propagar una idea revolucionaria en el imaginario político de una clase social corresponde a aquello que Sorel llama "mito" (1973, p. 29-41), es decir al mismo concepto cuya asociación con la política resulta, según Benjamin, radicalmente negativa. Dicho de otro modo, el medio puro de la política que según Benjamin representa la huelga general revolucionaria y que demostraría la existencia de acciones humanas que rompen con la hegemonía de la violencia jurídica, es teorizado en las Reflexiones de Sorel con el concepto menos oportuno para la crítica del filósofo alemán.

\footnotetext{
${ }^{3}$ La teoría de la huelga general proletaria circula entre los representantes de la llamada "Nouvelle École", Hubert Lagardelle y Edouard Berth, quienes publican junto a Sorel en la revista Le mouvement socialiste. A su vez, los grandes referentes de esta escuela son los apóstoles del sindicalismo revolucionario en Francia, Fernand Pelloutier y Aristide Briand, quienes crean la Fédération de Bourses de Travail en 1892 y forman en 1895 la Confédération Générale des Travailleurs (CGT), de carácter apolítico, anarquista y sindicalista. La teoría de la huelga general universal y revolucionaria proviene de sus escritos en la prensa sindical francesa de los años 1890. Comentando la historia del sindicalismo revolucionario, Jacques Julliard expone algunos términos de esta teoría: “[...] 4 millones de sindicalistas invirtiendo durante cinco años un monto anual de 20 francos reunirían una suma de 400 millones, a un ritmo de un poco menos de 3 francos diarios, lo que permitiría dar a cada uno de los 10 millones de personas que conforman la población obrera, un sueldo de 40 francos diarios correspondientes a quince días de huelga. Ahora bien, según nuestros autores [Pelloutier y Briand] es el máximo de tiempo necesario para que se derrumbe la sociedad burguesa" (JULLIARD, 1971, p. 73). Por otra parte, Pelloutier calcula una duración de quince días para el gran acontecimiento de la huelga general revolucionaria, referida al tiempo en que las arcas del Estado podrían mantener a sus fuerzas armadas (PELLOUTIER, 2005). Para un estudio sobre la prensa sindicalista y el imaginario social de este movimiento, véase la recopilación de textos de Miguel Chueca, Déposséder les possédants. La grève générale aux «temps héroïques» du syndicalisme révolutionnaire (2008).
} 
Quizás una nota a pie de página habría bastado para poner entre paréntesis este impasse teórico, este uso de una misma noción que describe realidades totalmente divergentes. Pero Benjamin simplemente pasa por alto la noción de mito en Sorel, volviéndola invisible por omisión. Esta omisión habilitaría la pregunta por el lugar teórico y práctico de la huelga general que coincide en los respectivos pensamientos políticos de estos filósofos, sabiendo que la noción de mito resulta problemática para dicha descripción. Dos vías se abren al respecto: por una parte, cabría consultar el trabajo de otros filósofos, lectores contemporáneos del tema "mito de la huelga general" de Sorel en el ensayo Para una critica de la violencia de Benjamin, con el fin de cotejar el modo en que ha sido estudiado este mismo problema; por otra parte, sería necesario seguir la traza que el propio Benjamin propone con la fórmula "medios puros de la política", como marco teórico de la huelga general en Sorel, citando para ello a otro filósofo alemán, Erich Unger. En lo que sigue de este artículo, indagaremos estas dos líneas.

\section{Lecturas contemporáneas sobre la relación entre Walter Benjamin y GeORGES SOREL}

En el marco de la bibliografía existente sobre el tema "huelga general" en Para una crítica de la violencia son pocos los autores que indican lo que el propio Benjamin dejó en silencio: que la huelga general proletaria en Sorel marca un punto de discordancia conceptual en el uso del término "mito". Por ello resulta relevante rescatar de esas lecturas los lugares teóricos donde estaría planteado este problema y donde serían señaladas, a la vez, las realidades llamadas con el mismo concepto equívoco de mito.

Entre tales lecturas se ofrecen algunas que, con mayor o menor profundidad de análisis, señalan los escritos involucrados que iluminarían la relación entre ambos filósofos, mientras otras irían más lejos al brindar hipótesis sobre la función que cumpliría Sorel en el pensamiento político de Benjamin. No obstante, en términos generales, se considera que la filosofía de la historia, la ética en la praxis política y la teología política serían las claves para pensar el problema de la huelga general en Benjamin y Sorel ${ }^{4}$.

\footnotetext{
${ }^{4}$ Cabe considerar la teoría del lenguaje inmersa también en la crítica benjaminiana, como primera variante de los medios puros. Para un estudio de la relación entre huelga general y teoría del lenguaje en Benjamin remitimos al remarcable artículo de Werner Hamacher, Afformative Strike (1991).
} 


\section{Reconocimiento del problema: Uwe Steiner y Antonia Birnbaum}

Uwe Steiner es uno de los pensadores que yuxtapone inmediata y explícitamente el tema de la huelga en Benjamin a la definición de mito en Sorel.

[Para una crítica de la violencia] invoca la concepción de la huelga general proletaria como un ejemplo sobre la posibilidad "de un ajuste de conflictos sin violencia”. En la huelga general proletaria, en tanto anarquista, el círculo encantado de la violencia se rompe en el momento en que el derrocamiento es producido por ella, y no incitado. Este pensamiento será más claro si se actualiza la definición de la huelga general de Sorel. Para Sorel, la huelga general es un "mito". Por mito entiende "una organización de imágenes capaz de evocar instintivamente todos los sentimientos que corresponden a las diversas manifestaciones de la guerra asumida por el socialismo contra la sociedad moderna”. (STEINER, 2004, p. 78)5.

Sin dar relevancia a la discordancia conceptual, Steiner sostiene la necesidad de adjudicar una función al mito de Sorel en el pensamiento de Benjamin, como aquel concepto que dilucida lo que Benjamin entiende por "ajuste de conflictos sin violencia". En este sentido, cobra valor la indicación de Antonia Birnbaum, al referirse a este mismo pasaje sobre la presencia de Sorel en Benjamin, no sólo planteando la línea de lectura sobre el mito, sino marcando oportunamente lo que Benjamin excluye.

[...] para Sorel la huelga proletaria es el mito por excelencia del movimiento proletario. Por mito, Sorel entiende en principio una imagen motriz: una salida del tiempo presente mediante la construcción de un futuro indeterminado. La huelga proletaria es "el mito en el cual el socialismo se encierra entero, es decir una organización de imágenes capaces de evocar instintivamente todos los sentimientos que corresponden a las diversas manifestaciones de la guerra emplazada por el socialismo contra la sociedad moderna" [...] En Para una crítica de la violencia, Benjamin no menciona jamás este aspecto. Lo que Sorel pone en la cuenta de una imagen que motiva, Benjamin lo refiere a técnicas de comunicabilidad que hacen la praxis de la huelga proletaria. (BIRNBAUM, 2008, p. 67).

Estas lecturas permiten establecer, por lo pronto, un primer vector sobre la huelga de Sorel en Benjamin, cuya definición asociada a la producción

\footnotetext{
${ }^{5}$ Todas las citas de este artículo han sido traducidas por nosotros, exceptuando las de Para una crítica de la violencia (BENJAMIN, 2009) y Reflexiones (SOREL, 1973).
} 
de imágenes y sentimientos, se trama en torno a la necesidad de hacer explícito un concepto excluido. Las pistas mencionadas tienden a remarcar el quiebre con un estado presente y la posibilidad inherente a un movimiento social de romper con un tiempo histórico. La zona oscura y sin mención del mito de la huelga de Sorel tomaría en Benjamin el valor de una praxis proveniente de un imaginario social, capaz de encarrilar una nueva temporalidad y, por consiguiente, de validar la pregunta por un nuevo concepto de historia.

\section{El mito de la huelga y la filosofía de la historia: Chryssoula Kambas y Daniel Bensaï̀}

En su estudio "Walter Benjamin lecteur de Georges Sorel", Chryssoula Kambas extiende este campo de investigación al señalar que la amplitud del mito de la huelga de Sorel tiene también cabida en los últimos escritos de Benjamin, precisamente en sus Tesis sobre el concepto de historia. Algunas de estas tesis estarían inspiradas en el filósofo francés, en particular la tesis XII que critica la noción de progreso en los políticos social-demócratas, tematizando la venganza, el odio y el sacrificio en la consciencia del espíritu de las clases combatientes, temas que fueron efectivamente abordados por Sorel en sus Reflexiones. Kambas remarca la ausencia de una referencia explícita al filósofo francés en las Tesis de Benjamin, pero esto tendría por causa la recepción problemática y equívoca de la obra de Sorel en Alemania en los años '30. Sin embargo, su influencia no sería difícil de probar si se considera el valor que adquiere en Benjamin la lucha de clases, siendo este conflicto histórico uno de los mayores motivos, afirma Kambas, por el cual Sorel seguiría siendo uno de sus referentes, así como los fenómenos de consciencia ligados a la acción política proletaria que "[...] pertenecen a la concepción soreliana del mito" (KAMBAS, 1984, p. 87).

En esta misma línea, en Walter Benjamin, sentinelle messianique, Daniel Bensaïd precisa los fundamentos conceptuales del pensamiento político de Benjamin, remarcando justamente la dimensión práctica de la huelga general de Sorel como manifestación histórica de un mito:

En el umbral del nuevo siglo, la huelga general, que se sitúa "entre la manifestación amenazante y la revuelta", emerge como el mito susceptible de cristalizar una voluntad de cambio. (BENSAÏD, 1990, p. 86). ${ }^{6}$

\footnotetext{
${ }^{6}$ Bensaïd señala igualmente el modo en que esta idea de una voluntad colectiva se refuerza gracias a la representación mítica de un porvenir desligado del concepto de utopía: “[...] el mito no se divide ni
} 
Parece quedar abierta ahí la posibilidad de que otros mitos hubieran cristalizado esa voluntad de cambio, lo cual resulta plausible desde la perspectiva de Sorel. En efecto, su teoría no concibe a la huelga general como la única práctica social en haber materializado un mito en la historia. Su punto de partida es más bien el de una interrogación hecha a la historia para "[...] saber qué mitos, en las diversas épocas, han llevado a un vuelco de las situaciones existentes" (SOREL, 1981, p. 337). En este sentido, un concepto de historia se deduce de aquellos movimientos sociales históricos que han socavado longevas instituciones de poder, cristalizando una voluntad colectiva reflejada en un imaginario mítico. El caso particular del sindicalismo revolucionario francés, cuyo imaginario propaga la idea de huelga general, sería el de una voluntad naciente inseparable de una tradición histórica de mitos sociales. La pregunta por la historia en Sorel sería así aquella que escruta el imaginario social de los movimientos sociales en pugna con el estado actual de cosas en crisis, en su vínculo eventual con una tradición de luchas históricas, también portadoras de representaciones míticas.

En este marco, cuando Bensaïd analiza el pensamiento político de Benjamin, es llamativo que contextualice la pregunta por la historia de este último referida también a un estado presente de cosas susceptibles de reavivar una tradición de luchas contra la clausura del tiempo histórico.

Bajo el choque de la primera guerra mundial, Benjamin plantea la pregunta correcta, aquella por la "filosofía de la historia". Una ética mesiánica implica una representación diferente del tiempo, donde lo que ha sido no es irreversible, donde lo que será no ha sido aún determinado. El pasado y el porvenir son puestos nuevamente en juego en el campo estratégico del presente. Sin la memoria de los ancestros sometidos, sin la interpretación de mañanas posibles, el presente sería pura gestión de medios, consumo ilimitado de la naturaleza, indiferencia cínica de una política utilitaria. (BENSAÏD, 1990, p. 198-199).

Aunque Bensaïd y Kambas no aborden directamente la discordancia conceptual sobre el mito y su omisión en Benjamin, valdría inferir de sus análisis el modo en que Benjamin acogería al fenómeno social de la huelga general revolucionaria como un movimiento que retoma las luchas históricas aún latentes y vivas en la lucha de clases, liberando al futuro de una proyección final fija. La teoría de los mitos de Sorel ocuparía, a fin de cuentas, el lugar de

se negocia. Expresión de una voluntad y no descripción de cosas futuras, el mito es una anti-utopía. Sin embargo, aún pertenece, junto a la utopía, a un imaginario pre-estratégico y pre-político. Con una diferencia importante: el mito no se evade en un futuro indeterminado." (p. 86) 
la filosofía de la historia en el pensamiento político de Benjamin, al romper con una concepción de la temporalidad recluida en un destino (mítico) supuestamente inquebrantable.

\section{Teorías del mito en Benjamin: Winfried Menninghaus}

La importancia del concepto de historia como clave de lectura del "mito" en Benjamin es también resaltada por Winfried Menninghaus, cuyo comentario nos resulta naturalmente significativo por el tema planteado en su título "Science des seuils. La théorie du mythe chez Walter Benjamin" ("Ciencia de los umbrales. La teoría del mito en Walter Benjamin”). En este artículo, Menninghaus realiza una verdadera cartografía de las tradiciones filosóficas y de las disciplinas científico-humanistas en torno al concepto de mito, particularmente de aquellas que entrarían en contacto con la filosofía de Benjamin. Para ello, expone siete teorías del mito, incluyendo las que Benjamin no pudo conocer durante su vida, para luego confrontarlas con su legado filosófico. Al compararlas, Menninghaus descubre un criterio capital: Benjamin desafectaría todas las definiciones de mito que se muestran indiferentes a una filosofía de la historia. Queda descartado así el mito de la tragedia en Nietzsche, que se sitúa más bien en una dimensión estética a-histórica; otro tanto sucede con el estructuralismo como clave de lo mítico, pues Benjamin estaría más interesado en la capacidad de universalización de concepciones formales que influencian la historia, que en la tesis de estructuras sociales que dan sustento a lo real. Según Menninghaus, las referencias benjaminianas con respecto al mito se dejan leer más bien en una línea genealógica proveniente de la Ilustración, el Romanticismo y la filosofía de la religión; aunque no descarta que su pensamiento encuentre ecos importantes en la teoría del mito de Freud, como también en Jung y aun en los surrealistas (MENNINGHAUS, 1986) ${ }^{7}$.

\footnotetext{
${ }^{7}$ La posición de Benjamin contra la violencia mítica, tal como la teoriza en Para una crítica de la violencia, se enraíza en la trama anterior, la de las fronteras epistemológicas entre la racionalidad de la Ilustración, el Romanticismo y la teología. Al respecto, la filosofía de Benjamin entre los años 19101920, según Menninghaus, se opone por una parte al carácter pre-lógico de las representaciones míticas juzgado por la tradición ilustrada (que empobrece el concepto de experiencia), pero por otra parte moviliza la misma racionalidad ilustrada contra la locura romántica del mito, cuya restitución poética podría aun ponerse a disposición de una política reaccionaria. En este sentido, Benjamin (bajo la influencia de Hermann Cohen) sitúa a la religión en el lugar de la Ilustración para reivindicar la verdad ligada al logos que se separa tanto de lo profano como de lo mítico, adquiriendo un valor divino mediante la idea de revelación (MENNINGHAUS, 1986).
} 
Sin embargo, llama la atención en este análisis una ausencia sensible: si las concepciones del mito mencionadas deben vincularse o desafectarse del pensamiento de Benjamin en función de su relación con la filosofía de la historia, Menninghaus no hace ninguna mención del mito de la huelga general en Sorel. Por cierto, no nos parece que esta ausencia pueda reprocharse al autor, más aún si recordamos que es el propio Benjamin quien decide omitir de su ensayo el mito de Sorel. De todos modos consideramos que la filosofía de la historia contenida en el mito de Sorel sería desde ya un complemento para la remarcable cartografía de las teorías del mito en Benjamin realizada por Menninghaus, en miras a elucidar su relación con el mito de la huelga.

\section{Praxis ética y mito: Carlo Salzani}

Junto con Antonia Birnbaum, Carlo Salzani es también uno de los pocos filósofos en subrayar la existencia de la discordancia conceptual entre Benjamin y Sorel referida a la noción de mito. Al respecto, considera como un error descartar esta noción por la mera falta de un punto en común en ambos registros.

Benjamin y Sorel proponen dos definiciones de mito que no representan una alternativa, aún menos una oposición; más bien se trata de concepciones heterogéneas que adoptan roles divergentes e incluso incomparables en sus respectivos pensamientos. Sin embargo, afirmar que Benjamin asume la noción de huelga general sustrayendo el mito sería impreciso. Las dos nociones de mito deben ser analizadas en relación a la noción de praxis en tanto acción moral con la cual éstas constituyen una complejidad inseparable. (SALZANI, 2008, p. 46).

Salzani aborda este análisis de una praxis moral política primeramente en Benjamin. Para ello procede como varios otros lectores que indagan dicha temática en el filósofo alemán definiendo el perímetro de sus escritos durante los años '20: Para una crítica de la violencia, Destino y carácter y Las afinidades electivas de Goëthe. Destino, culpabilidad y deuda son las categorías míticas referentes a las potencias que se ciernen sobre la vida humana, delineando a la vez aquel dominio cuya destrucción representaría en Benjamin una praxis ética: la supresión de un orden superior arbitrario por la emancipación de la vida justa.

Lo "mítico" es la prisión de la vida reducida a la "vida natural", es decir a la "simple vida", la culpabilidad, la mala fortuna que se ensaña sobre el humano y que lo lleva al desastre: es la recurrencia eterna de la violencia. La esfera ética se abre en la ruptura del complejo demoníaco mito-destino- 
culpabilidad que representa propiamente a la vida natural, una ruptura en "algo superior": la vida sobrenatural, una vida propiamente humana que podría realizar una historia propiamente humana. (p. 27).

Desde la perspectiva de Sorel, Salzani observa el tema de la praxis como lugar común al pensamiento político de Benjamin en la medida en que refiere igualmente a la ruptura moral con un estado actual de cosas.

Por su parte, en el mismo terreno de la práctica moral, lo que Sorel llama mito actúa como una suerte de impulso por romper la inercia de una adversidad. En tanto condición previa para la práctica revolucionaria, el mito debe proveer una certeza sin ser determinista, y emociones movilizadoras sin proponer imágenes del futuro. Es por esto que el recurso a las utopías o al optimismo de las filosofías del progreso es descartado. Sólo el poder catalítico del imaginario mítico conlleva la caída de la violencia estatal. (p. 29-30).

Contra la crítica del carácter irreal de estos mitos, Salzani recalca que para Sorel estos sistemas imaginarios no son hechos ni ilusiones, pues por mucho que no realicen las imágenes que anuncian, nunca plantean un programa a verificar en el porvenir, sino una praxis que determina las condiciones del tiempo histórico.

[El mito es] un conocimiento que actúa sobre el tiempo, que evita engullirlo en una proyección utópica [...], más bien sitúa en el porvenir las esperanzas instintivas de toda una clase. Los mitos deben ser considerados como "medios de actuar en el presente" [...]. La condición necesaria de la praxis pura revolucionaria es de "salir del presente" y de "construir" el futuro de una manera que no está desde ya determinada (p. 31).

La marca de la acción política ética en la temporalidad representa, a fin de cuentas, el impacto de la misma en la historia. Se suturan así estos dos campos filosóficos, el de la acción moral y la temporalidad histórica. Así, desde el punto de vista de la historia, la idea de mito en Sorel no tiene ni origen ni fin, pues sería indeterminada e indefinida en su relación al pasado y al futuro (p. 44); y desde el punto de vista de la acción moral política, el mismo mito es una práctica ética pura con consecuencias actuales y libre de un carácter facticio e ilusorio, así como de un uso instrumental (p. 31). Esto equivale 
a decir que para la historia, este mito es al mismo tiempo anárquico y no teleológico; y para la política, es una práctica pura, sin intereses ocultos.

Tales fundamentos de la idea de mito estarían activos en el pensamiento político de Benjamin, en particular en su modo de concebir la pureza de una acción (como lo atestan las nociones de "medios puros", "lenguaje puro" o "violencia pura" que aparecen en Para una crítica de la violencia). El argumento de Salzani expone en última instancia la relación entre Benjamin y Sorel en función de una simetría en sus modos de concebir una práctica moral y pura en la historia: si el mito de Sorel es tanto anárquico como no teleológico, la idea que se hace Benjamin de la huelga, como praxis moral y concepto de historia, respondería a estos mismos atributos.

\section{El TIEMPO MESIÁNICO CONTRA EL TIEMPO HISTÓRICO: GÉRARD RAULET}

En Le caractère destructeur, Gérard Raulet plantea también la necesidad de considerar la función del mito de Sorel en el pensamiento político de Benjamin, con un ajuste en lo que respecta a la tesis de Salzani: si bien habría un anarquismo en esta secuencia de la huelga revolucionaria en Benjamin, el problema comprometería otro aspecto de la temporalidad humana.

[...] no sería ilegítimo estimar que aquella idea movilizadora del movimiento obrero que Sorel llama "mito", corresponda en Benjamin a la función del mesianismo. (RAULET, 1997, p. 219).

Esta indicación tiene varias implicancias, pues marca una distancia respecto a una supuesta anti-teleología en la filosofía de la historia de Benjamin, tal como era señalado por Salzani. Para Raulet, por mucho que la huelga en su praxis comprometa la temporalidad humana, no lo hace precisamente en su cifra histórica, sino mesiánica, lo cual conlleva que la praxis ligada al mito de la huelga no significaría necesariamente la retirada de una teleología. Esto se podría inferir de una distinción hecha por Benjamin en un escrito datado, según su amigo Gershom Sholem, en los años '20, cercano a la publicación de Para una crítica de la violencia: el Fragmento teológico-politico. Ahí Benjamin sostiene que el tiempo comprometido con la llegada del Mesías es ya el del fin de la historia (1989, p. 193-194; 1991, p. 203-204). La operación reflexiva consistiría en pensar la idea universal de la huelga en el lugar de la redención mesiánica por venir, lo que corresponde a la proyección de un telos en un tiempo en el que no 
corre más la historia. Su expresión efectiva se daría en la inversión del aspecto práctico de la huelga (cesación general del trabajo) en la acción revolucionaria que deserta el tiempo histórico del progreso, en favor de la espera mesiánica. Así, el mito de la huelga general no sólo consistiría en una interrupción de las utopías, sino también, y por sobre todo, en una experiencia que suspende toda finalidad histórica de la humanidad, manteniendo un telos redentor.

Ahora bien, si aquello que marca el mito soreliano es el fin mesiánico y no el histórico, y si esta operación determina la clave del concepto de historia en Benjamin (temporalidad de la espera y proyección de la redención), cabría verificar también cómo se conjuga esta filosofía de la historia con la praxis moral de la huelga revolucionaria. La hipótesis de Raulet al respecto entronca con la de Chrysoula Kambas sobre la necesidad de pensar la lucha de clases como el nexo entre Sorel y Benjamin. En efecto, si existe una praxis moral de la política pensada por Benjamin, ella debe vincularse, según Raulet, a la huelga proletaria como una "ética de la lucha de clases".

Esta ética de la lucha de clases evidentemente no tiene nada que ver con el judaísmo edulcorado que nos proponen ciertos intérpretes de la ética benjaminiana que quieren ocultar absolutamente la lucha de clases. (RAULET, 1997, p. 271).

La lucha de clases sería así el verdadero filtro para cualquier revisión del pensamiento político de Benjamin en los años '20: por una parte se trata del conflicto histórico que determina a la huelga general como medio puro de la política, por la otra es, según Sorel, el principio motor del mito social de toda esta época. En última instancia, la lucha de clases corresponde a la praxis que marca la función del mito en el pensamiento de Benjamin, a la vez como ética política y como filosofía de la historia, en tanto actualiza la tradición de movimientos sociales históricos por la emancipación de la vida sometida a un orden superior. Visto así, el debilitamiento de la lucha de clases encarnado en la represión de las huelgas generales de la época, representa para estos filósofos el peligro histórico mayor con el cual se encuentran intelectualmente comprometidos, en la urgencia de pensar la adversidad política en la violencia que dominaba el comienzo del siglo XX. 


\section{UNA POLÍTICA DE MEDIOS PUROS: ERICH UNGER}

Como lo habíamos señalado, Benjamin también estaría en condiciones de responder, al menos indirectamente, a la pregunta por la función del mito de Sorel en su pensamiento político. Esto se da en un pasaje puntual de su ensayo Para una critica de la violencia, donde esboza la trama conceptual cuya figura referencial sería la huelga general: la política de los medios puros.

Para mover a los seres humanos al arreglo pacífico de sus intereses más acá de todo orden legal, hay después de todo, y con prescindencia de todas las virtudes, un motivo eficaz, que muy a menudo suministra incluso a la voluntad más áspera aquellos medios puros en lugar de violentos, por temor a las desventajas comunes que amenazan con surgir de la confrontación violenta, como quiera que resulte. Claramente se presentan en incontables casos a propósito del conflicto de intereses entre personas privadas. Distinto es cuando clases y naciones se hallan en disputa, con ocasión de lo cual aquellos órdenes superiores que amenazan con sobrepujar por igual al vencedor y al vencido, quedan ocultos al sentimiento de la mayoría y a la inteligencia de casi todos. Aquí la búsqueda de tales órdenes superiores y de los intereses comunes que les corresponden, los cuales proporcionan el motivo más persistente para una política de los medios puros, nos llevaría demasiado lejos. Por ello, bastará remitir solo a los medios puros de la política siquiera como análogo de aquellos que gobiernan el trato pacífico entre personas privadas.

En lo que atañe a las luchas de clase, la huelga tiene que valer en ellas, bajo ciertas condiciones, como un medio puro. (BENJAMIN, 2009, p. 439, la negrita es nuestra).

Sabemos que Benjamin usa esta figura de los "medios puros" aludiendo a aquellas instancias creadas por la humanidad para resolver sus conflictos, al margen de cualquier marco normativo existente. ¿Pero qué se entiende más precisamente aquí por medio puro de la política? En principio, se trataría de la singularidad de aquellos conflictos, cuya escala sobrepasa la de los asuntos privados involucrando clases y naciones, especialmente en lo que Benjamin llama "órdenes superiores" e "intereses comunes". Al respecto, se deducen dos vías de análisis, una más extensa que la otra: la vía abreviada es la que Benjamin despliega, sirviéndose de la analogía que habría entre medios puros entre privados (técnicas de comunicación) y medios puros de la política (la huelga general "bajo ciertas condiciones", que corresponderá a la huelga teorizada por Sorel); la vía extensa, que lo llevaría "demasiado lejos", es la que estaría nombrando con la fórmula "política de medios puros", sobre la cual 
Benjamin remite inmediatamente en una nota a pie de página a la obra de otro filósofo: “[...] ver Erich Unger, Politik und Metaphisyk, p. 18 y ss.” (p. 439)

En este contexto, la pregunta por una "política de medios puros" se desplaza entonces a Unger, cuya obra Politik und Metaphysik, de difícil acceso y sin traducción a la fecha, marcaría una influencia decisiva en la redacción de este ensayo y respondería, en particular, a nuestra interrogación por la función del mito de la huelga general de Sorel como un "medio puro de la política". Dicho sea de paso, cabe consignar que no se trata de la primera referencia a Unger en Para una crítica de la violencia. En un pasaje contra el parlamentarismo (sobreentendiendo la actualidad de la República de Weimar), Benjamin ya citaba la fórmula "política de compromisos" usada por Unger para caracterizar este régimen (p. 437). La importancia del pensamiento político de Unger es seńalada además por el propio Benjamin en una de sus correspondencias con su amigo Gershom Scholem (carta de enero de 1921):

A propósito, he conocido recientemente un libro que, según puedo juzgar después de haber ido a dos de las conferencias de su autor, parece ser el escrito más significativo sobre política de este tiempo. En la tarde de ayer, durante su segunda conferencia, Hüne Caro me ha dicho haberle escrito a usted sobre el libro de Erich Unger, Politik und Metaphysik. (BENJAMIN, 1978, p. 252). ${ }^{8}$

Teniendo en cuenta estos antecedentes, nos parece necesario indagar la pista poco explorada del trabajo de Unger en las lecturas contemporáneas de Para una crítica de la violencia, tarea que abordaremos en esta parte final del presente artículo.

\section{UNGER Y LA FILOSOFÍA DE LA HISTORIA}

La fórmula "política de medios puros" no está enunciada en estos términos por Unger en las páginas citadas por Benjamin. Sólo la problemática general del libro permite deducir su interés por esta idea de la política. Politik und Metaphysik aborda como temática principal el peligro de una

\footnotetext{
${ }^{8}$ Los editores de esta correspondencia (T. W. Adorno y G. Scholem) completan la referencia a la primera edición de esta obra de Unger - "Berlin, 1921" - señalando que se trata de un escrito casi imposible de hallar (BENJAMIN, 1978, p. 252).
} 
política cuya concepción de mundo estaría desligada de la metafísica? Tal separación generaría dos líneas paralelas del quehacer humano, una material y otra inmaterial, cada una de las cuales estaría supeditada a un orden superior: en el plano inmaterial dominaría lo espiritual; en el material, los intereses económicos. Esta separación se traduce, según Unger, en una política catastrófica, no en el sentido de acabar o de destruir un mundo bien constituido, sino en el de mantener eternamente a la humanidad y su historia en la tendencia hacia un estado ideal deseable sin jamás llegar a concretarlo. Sería esta la concepción del tiempo histórico del progreso y del éxito, de las etapas que deben ser cumplidas para alcanzar el momento final de un mundo logrado y en equilibrio.

Para describir esta concepción problemática de la historia, Unger plantea una lectura política y ética de las temporalidades históricas en tensión, explorando tanto el funcionamiento de una política separada de la metafísica, como la perspectiva de una política fusionada a una posible experiencia metafísica, particularmente en aquella discusión de época en torno al problema "psicofisiológico" (volveremos más adelante sobre este punto). Una "política de medios puros", en sintonía con Benjamin, se ligaría manifiestamente a esta crítica de Unger sobre la separación entre política y metafísica, con eje en la filosofía de la historia y en la ética de la acción política.

En lo que respecta particularmente a su lectura de la historia, cabría apuntar el problema de los dos estigmas que marcan, según Unger, la temporalidad humana: el fracaso y el éxito.

[...] nuestro razonamiento se dirige en principio a aquellos que no encuentran en los hechos políticos de la humanidad otras fuerzas productivas y éticas que no pertenezcan al pasado y por las cuales "la historia" no tiene otro sentido que el de una "historia del fracaso". La historia que se descuelga de la norma ética es un despliegue cuyo estigma es el fracaso (mientras que el mito es un despliegue cuyo estigma es el éxito). (UNGER, 1989, p. 8).

\footnotetext{
${ }^{9}$ Un dato importante a considerar es un escrito filosóficamente fundacional del pensamiento de Benjamin, "Programa sobre la filosofía venidera" de 1917, donde Benjamin plantea la necesidad de expandir el concepto empobrecido de experiencia en la teoría kantiana del conocimiento (limitado a las leyes mecánicas de la física), hacia la posibilidad de una experiencia en el dominio de la metafísica, una experiencia religiosa (BENJAMIN, 1998, p. 75-84). La unión entre política y metafísica que Benjamin remarca en Unger coincide precisamente con este programa.
} 
Un concepto positivo de la política (que Benjamin asociará al tema de los medios puros) ha de entenderse aquí, por lo pronto, en oposición a lo que sería la política ligada a la temporalidad dominante en la historia: el éxito mítico. Este estigma tiene que ver, según Unger, con la proyección de una finalidad histórica ideal para la humanidad, un estado de perfección sobre el cual no se puede saber si corresponde al final o al comienzo de un mundo. $\mathrm{Al}$ respecto podría objetarse la inexistencia de una experiencia humana que asegure la llegada a un estado ideal; pero la perspectiva del éxito, pese a esta ausencia de pruebas, tiene que ver más bien con la existencia previa de otras finalidades reales ya cumplidas y que estarían objetivamente encaminadas hacia dicha meta ideal. A estas estaciones de la teleología histórica, Unger las llama "puntos intermediarios" (Zwichenpunkten), refiriendo con ello al movimiento lanzado hacia un fin ideal, detenido en la primera "pausa de descanso" (Ruhepause). Dicho de otro modo, la política del tiempo mítico determina la tendencia histórica hacia una culminación ética, estancada en cualquiera de los puntos intermediarios que a ella conducen.

Por su parte, la perspectiva del fracaso, que también es un signo característico (estigma) de la historia, refiere a aquellas acciones que históricamente han demostrado ser experiencias vividas de un mundo ético en un tiempo presente, pese a haber sido derrotadas en sus intentos por establecer aquí y ahora otro modo de vida. Esta tradición de movimientos éticos, que es la de las luchas sociales, provee pruebas empíricas de la posibilidad de una praxis ética actual de la humanidad, sin necesidad de proyectarse en una realización ideal venidera.

Así, desde esta primera perspectiva que corresponde en su conjunto a una filosofía de la historia, una política de medios puros consistiría en una operación relativa al modo de concebir la temporalidad de la humanidad: por una parte, abandonar aquel método exitoso de aproximación hacia un fin histórico que compromete generación tras generación, desertando el plan de cumplir un proceso histórico por etapas; y por la otra, rescatar el aspecto moral de las luchas históricas, cuyo fracaso o interrupción temporal, según Unger, representa "una mediocridad más ética y más heterogénea". No obstante, persiste en esto un problema, que es el de saber si la ética debe anclar en esta idea de fracaso por el mero hecho de referir a la tradición de luchas sociales derrotadas. ¿No queda acaso abierta la interrogación por lo que interrumpe el movimiento de una lucha, por aquella instancia que inflige el estigma del fracaso ético de la historia? 


\section{ÓRDENES SUPERIORES E INTERESES COMUNES: LA ÉTICA DE LA LUCHA CONTRA LA ÉTICA PACIFISTA}

Justamente ante esta pregunta adquiere relevancia la referencia hecha por Benjamin a los "órdenes superiores" y los “intereses comunes" que estarían representados en los conflictos políticos y que serían "el motivo más persistente para una política de medios puros". Al respecto, cabría indicar que la política catastrófica de la temporalidad mítica marcaba para Unger un problema contemporáneo, razón por la cual su crítica filosófica apuntaba efectivamente a una trama política actual: la democracia parlamentaria de la República de Weimar ${ }^{10}$. Este régimen sostenía la vía reformista, factible de traducirse en una programación de etapas intermediarias que apuntaban a generar de un modo pacífico y progresivo las condiciones para un mundo socialista, evitando presumiblemente el camino de una revolución violenta. Pero más allá de la coyuntura histórica, para Unger el problema medular del parlamentarismo tenía que ver con la esencia de la política de partidos. Por "partido", Unger entiende un fragmento de rectitud incompatible con aquellos fragmentos de rectitud de otros partidos, es decir una serie de directrices políticas basadas en principios diversos y aun opuestos entre sí, razón por la cual su confrontación resulta ineludible. Sin embargo, tales fragmentos de rectitud no harían sino cubrir lo que sería un fundamento mayor ineluctable:

La economía es, por lejos, la explicación mayor y la más plausible de casi todos los comportamientos políticos [...] El problema de cada partido se encuentra simplemente en poder formular su interés privado lo más cercano que sea posible a una validez universal [...] Y es una excepción cuando el interés económico no ordena la dirección política. (p. 11).

El parlamentarismo se presenta entonces como el espacio político en el cual las diferencias fundamentales entre partidos, motivadas por intereses económicos, se proyectan para la solución de conflictos en un marco pacífico y sin violencia. Sin embargo, lo que aparece aquí no es un lugar pacífico y resolutivo de conflictos políticos a escala social, sino un orden que se superpone del modo más brutal a otro orden, el de los verdaderos conflictos

\footnotetext{
${ }^{10}$ Valga recordar brevemente la secuencia histórica de crisis económica y política a fines de la Primera Guerra mundial en Alemania, que conoce la proclamación de la República libre socialista sostenida por el movimiento revolucionario espartakista, crudamente reprimido en 1919 (asesinatos de eminentes figuras de la intelectualidad alemana vinculadas al comunismo y al anarquismo, como Rosa Luxemburg y Gustav Landauer) y sobre la cual se instituye en seguida el régimen socialdemócrata y parlamentario de la República de Weimar.
} 
existentes entre clases. A este mecanismo de superposición violenta, propio del parlamentarismo, Unger lo llamará "política de compromisos". Con esto se refiere a la pretensión de reunir en un solo escenario político (parlamento) la representación de intereses económicos en un lugar de negociación y aun de alianzas entre posturas contrarias, instituido bajo una condición sine qua non, pacífica en apariencia: la renuncia del resto de los hombres a negociar o a entrar en conflicto sobre sus propios diferendos, sean estos sociales o económicos.

Uno de las trabas que debe sortear esta política parlamentaria es la de mostrarse como un espacio ético. Según Unger, al buscar la forma del acuerdo sobre un problema, el compromiso transforma aquello que sería una solución directa de conflictos en un equilibrio de fuerzas, de tal suerte que el conflicto de fondo se mantiene y aún más, nunca se resuelve. Se sigue de esto que "gobernar" signifique aquí la conservación y a la vez el encubrimiento de una tensión real, mediante la generación de un equilibrio de fuerzas en una instancia representativa. Así, el mero hecho de guardar la tensión de un conflicto puede tomar la apariencia ética de una lucha justa y pacífica de intereses divergentes, mientras que la lucha en su realidad (es decir, el verdadero lugar resolutivo de un conflicto) es desarticulada por la escena política del compromiso.

¿Cómo es posible que a partir de este simple recurso deba generarse un momento ético, es decir cómo puede ser eliminado el carácter de la lucha en la cual el más fuerte vence y el más débil sucumbe? [Esto se revela] por la conversión del antagonismo directo de las capas económicas en el de sus representantes. Pero el carácter de la lucha no debe ser eliminado de ningún modo, y es esta la razón por la cual es necesario consolidar el signo de la "lucha pacífica", que es el compromiso sobre el cual los socios deben unirse. Ahora bien, la "lucha pacífica" o el compromiso, elemento principal de la política actual, es el combate latente abierto; y es que el compromiso debe ser siempre violencia diferida, al tratarse de la unión momentánea de dos enemigos cuando la superioridad de uno no es suficiente; incluso si se desdeña toda violencia abierta, el compromiso sigue siendo el producto subyacente a la mentalidad de la violencia, porque la tendencia que lleva a un compromiso no viene espontáneamente de sí misma, sino del exterior, es decir de una tendencia contraria, pues en todo compromiso, por muy voluntario que haya sido efectuado, la naturaleza coercitiva no puede ser eliminada del pensamiento. "Hubiera sido mejor de otro modo": este es el sentimiento profundo de todo compromiso. (p. 12). ${ }^{11}$

\footnotetext{
${ }^{11}$ Este es precisamente el pasaje citado por Benjamin en su primera referencia a Unger. (BENJAMIN,
} 2009, p. 437). 
La pregunta proveniente del texto de Benjamin por el orden superior y los intereses comunes que sobrepasan tanto a vencedores como vencidos halla una imagen paradigmática en la instauración del régimen parlamentario (plasmado en esta secuencia histórica precisa de la reacción política socialdemócrata contra la Revolución Espartaquista de Alemania) como un mecanismo de poder que ahoga la lucha de clases sin resolverla, reemplazándola por un espacio de conflictos sin conflicto. Desde el punto de vista de una acción política ética e histórica, se exponía temporalmente el hundimiento violento de un movimiento radical y revolucionario que involucraba directamente a las clases en su rol político histórico, en manos de un ideal pacifista que redujo el conflicto a un equilibrio de fuerzas representadas: la ética pacifista superpuesta con violencia a la ética de la lucha de clases. "Orden superior" significa entonces el establecimiento y la conservación de una instancia que suplanta la realidad de los conflictos sociales mediante su representación, anulando lo que sería su resolución inmediata en la lucha política.

Por esta razón, la cercanía de una política no-catastrófica con algunas corrientes del comunismo y del anarquismo, tal como lo pensaba Unger, se ligaba a aquellos movimientos sociales al margen de un orden superior (es decir al margen de cualquier instancia que hipoteca el tiempo presente por un estado ideal futuro) favoreciendo la tendencia histórica ligada inmediatamente a la solución de un conflicto social en el despliegue de su propio movimiento.

Ahora bien, si volvemos a la perspectiva de Benjamin sobre este punto, es posible entrever, por una parte, su empatía con la crítica de Unger a los "órdenes superiores", en tanto representa su propia distinción entre "violencia instauradora de derecho" y "violencia conservadora de derecho"; y por la otra, se entiende también la referencia a Sorel y a su modo ingenioso de evacuar la violencia de la huelga revolucionaria, pues responde precisamente al medio por el cual es posible eludir el "orden superior" del Estado, es decir del poder que intervenía y desvirtuaba la lucha de clases (sea como mediador entre el proletariado y la burguesía), interponiendo objetivos intermediarios (creación de leyes sindicalistas o de un derecho a huelga).

\section{El PROBLeMA PSICOFISIOLÓGICO Y EL CUERPO DE LA POLÍTICA}

Además de la filosofía de la historia, de la posibilidad de una praxis ética y del distanciamiento de una política determinada por órdenes superiores e intereses económicos, cabría señalar aún otro aspecto del pensamiento de 
Unger, en consonancia con una política de los medios puros: el problema psicofisiológico, es decir, el de la relación entre mente y cuerpo.

Ya hemos señalado que para Unger la catástrofe de la historia ligada a un movimiento eternamente separado de su propia finalidad ideal tiene que ver con la separación entre metafísica y política. Un modo de argüir esta separación se daría al afirmar que la política secular occidental toma efectivamente su imagen del orden espiritual, o dicho en clave moderna, la naturaleza se ordenaría jerárquicamente del mismo modo que lo hace el pensamiento, habiendo entre uno y otro una relación especular. Unger no negará este vínculo analógico entre pensamiento y naturaleza. Sin embargo, romperá con la idea de jerarquía en coherencia con su crítica de todo orden superior, de modo tal que la relación material entre mente y cuerpo no se leería en términos de voluntad. Antes que obedecer y aplicar mecánicamente una orden, el cuerpo se relaciona con la mente de un modo orgánico, es decir, en atención a una totalidad dependiente de cada una de sus partes. Esta tesis es crucial, ya que repercute en la imagen de la sociedad como cuerpo. Si el cuerpo fuera una estructura mecánica, sería plausible distinguir la instancia superior (superestructura) de un orden al cual las instancias menores (infraestructuras) habrían de responder. Para Unger, el cuerpo es un todo orgánico articulado, por lo que la disfunción de un solo órgano afecta a la totalidad de su funcionamiento. El argumento de Unger defiende así, ciertamente, la idea de una política a imagen del cuerpo, pero a diferencia de la política secular, la racionalidad del cuerpo político estaría ligada al funcionamiento de las diversas partes que lo articulan. Es por esto que la política entendida exclusivamente con relación a intereses económicos, es decir a una sola de sus partes, resulta ser catastrófica no sólo en su manera de entender "mecánicamente" el funcionamiento de las relaciones sociales, sino sobre todo en su modo de reducir el significado mismo de lo político y de ignorar la potencialidad de la razón en este cuerpo constituido de múltiples componentes orgánicos.

En esta misma línea, Margarete Kohlenbach señala, en su estudio sobre la relación filosófica entre Benjamin y Unger, a partir de la perspectiva de este último, que el lugar donde el pensamiento concretaría realidades, es decir su praxis relativa a la realización de un universal concreto, no sería la tecnología, tal como lo es para la ciencia, sino la política (KOHLENBACH, 2005, p. 76). La política consiste en concebir la construcción de un organismo social sin órdenes superiores que impongan un funcionamiento al resto de las partes. En este sentido, para el filósofo del judaísmo que era Unger, al igual que para 
Benjamin, el problema consistía aquí en pensar la construcción política del pueblo judío sin Estado, contexto en el cual Unger movilizaba el concepto de Volksgeist, espíritu del pueblo (KOHLENBACH, 2005, p. 78). Por esto mismo, ante la disyunción entre lo espiritual orgánico incorporado a la política y la comprensión secular de la política en la modernidad europea, Unger se inclina por la primera, por la sola tendencia catastrófica de la segunda, cuyas invocaciones a la racionalidad humana no tienen ningún efecto real. Pensar un cuerpo político implica dar con el lugar de su experiencia espiritual, con la mente colectiva en el seno de la cual se piensa a sí misma y en el que presta atención a todo aquello que lo articula. Pero mientras la política y la metafísica permanezcan desunidas, el único sentimiento positivo será, según Unger, el pesimismo, es decir la única seńal racional histórica a reconocer como punto de partida actual para una posible política no-catastrófica.

Ahora bien, justamente el tema del pesimismo cultural marca, según Kohlenbach, el lugar teórico donde Benjamin se encuentra con el pensamiento de Unger (KOHLENBACH, 2005, p. 79-80), la actitud espiritual que expresa verdaderamente la potencia de la política y su atención ampliada a las partes que constituyen su cuerpo. Esta clave del sentimiento pesimista explicaría a la vez dos puntos relevantes de nuestra interrogación sobre los medios puros de la política, correspondientes a la posibilidad de una política no-catastrófica en Unger. En primer lugar, da cuenta de la causa por la cual Unger rompería con una cierta lectura del marxismo, a saber aquella que relega en Marx lo religioso-espiritual como un epifenómeno de la política, evacuando la potencia metafísica de esta última. Por esto también, la preponderancia del interés económico por sobre cualquier otro en el materialismo marxista sería un aspecto que provoca igualmente el alejamiento de Unger, por la misma operación políticamente reduccionista que esta relación presupone. Esto nos lleva al segundo punto, que concierne la perspectiva de Benjamin y Sorel, tanto por el tema del pesimismo que, en Sorel, es una condición insoslayable en el imaginario mítico de un movimiento revolucionario (SOREL, 1973, p. 16), como por la referencia a un materialismo que sobrepasa la referencia a la lucha de clases entendida como lucha de intereses económicos. El mismo imaginario pesimista presente en la concepción de la huelga general revolucionaria es un factor que no está ligado inmediatamente al aspecto material económico, sino al modo de descartar la incorporación de un orden superior y regulatorio del conflicto histórico. Por lo demás, un materialismo ampliado en su modo de concebir la política se perfila en el tema mismo de los medios puros en Benjamin, es decir, en la amplitud que pueda cobrar la definición de un 
conflicto para la humanidad. Desde la perspectiva de Unger, esto supone desde ya abrir la puerta a lugares del quehacer humano que tienen que ver directamente con la injerencia del espíritu en el cuerpo, es decir al perímetro que pueda abarcar la ciencia del problema psicofisiológico, desde la psicología a la sociología, desde la antropología a la biología. Una política de los medios puros es, en este sentido, la fórmula desde la cual se perfila desde ya la política como biopolítica, en un materialismo con fronteras extendidas a la naturaleza de cualquier conflicto frente al cual la humanidad precise soluciones.

\section{Conclusión}

Es innegable que el análisis de Benjamin sobre la huelga general revolucionaria (mito de Sorel) abrevia lo que sería el análisis de una política de los medios puros en Unger. Para este último, la perspectiva de una política no catastrófica y no violenta es posible, a condición de repensar, por una parte, una filosofía de la historia y una praxis ética, y por la otra, el concepto mismo de lo político más allá de la estrecha frontera económica. La conjunción de estas perspectivas lleva implícita una lectura crítica del marxismo, cuya condición sería la de renunciar a la ambición de instaurar un orden superior desde el cual conducir teleológicamente un fin ideal por venir. Repensar el marxismo no quiere decir abandonar la perspectiva de la lucha de clases, sino, bien por el contrario, extender el campo de los conflictos donde se pone en juego esta lucha que ya, en los albores del siglo XX, sobrepasaba el de los intereses económicos. En esta trama, la huelga general, mito social o medio puro, representa un lugar de transformación simultánea de la filosofía de la historia, de la ética y de un concepto dogmático de la política.

PÉREZ LÓPEZ, Carlos. Walter Benjamin and Georges Sorel: between the myth of the general strike and a politics of pure means. Trans/Form/Ação, Marília, v. 38, n. 1, p. 213238, Jan./Abr., 2015.

ABSTRACT: In his Critique of violence, Walter Benjamin claimed that the social phenomenon of the revolutionary general strike (theorized on by Georges Sorel in his Reflections on Violence) was an example of what would be a "pure political mean" (outside any legitimate form of power). In this context, not many contemporary commentators note an important conceptual incoherence between those two philosophers: for Sorel the revolutionary general strike is a social myth, while in Benjamin 
the category of myth, essentially negative, describes the violence that imprisons life and crystallizes it in a higher form of political power. In this article, we demonstrate this conceptual discrepancy in order to examine the way it has been approached by other philosophers. The philosophy of history, the possibility of an ethical political action, and messianic temporality, all appear on the theoretical horizon linking these philosophers, and through these ideas a conceptual impasse can be decoded. Moreover, this horizon can be confirmed if we follow the idea of a "pure political means" that Benjamin proposes and which moves forward to the thought of an unexplored philosopher mentioned by him: Erich Unger. In the last part of this article we will develop the keys given by Unger, which fall right in line with the notion of the general strike as a pure political mean.

KEYWORDS: Walter Benjamin. Georges Sorel. Erich Unger. General Strike. Myth.

\section{BibLIOGRAFÍA GENERAL}

BENJAMIN, Walter. Briefe I. Frankfurt am Main: Suhrkamp, 1978.

. Gessamelte Schriften, II-1. Frankfurt am Main: Suhrkamp, 1991.

. Para una crítica de la violencia. Trad. De Pablo Oyarzún. Archivos, n. 2/3, p. 425452, 2009 .

BENSAÏD, Daniel. Walter Benjamin, sentinelle messianique. Paris: Plon, 1990.

BIRNBAUM, Antonia. Bonheur Justice Walter Benjamin: le détour grec. Paris: Payot et Rivages, 2008.

JULLIARD, Jacques. Fernand Pelloutier et les origines du syndicalisme d'action directe. Paris: Seuil, 1971.

KAMBAS, Chryssoula. Benjamin lecteur des "Réflexions sur la Violence". In: Mil neuf cent. Revue d'histoire intellectuelle. Cahiers Georges Sorel, v. 2, p. 71-89, 1984.

KOHLENBACH, Margarete. Religion, experience, politics: on Erich Unger and Walter Benjamin. In: KOHLENBACH, Margarete; GEUSS, Raymond (Eds.). The Early Frankfurt School and religion. New York: Palgrave Macmillan, 2005. p. 64-84.

MENNINGHAUS, Winfried. Science des seuils: la théorie du mythe chez Walter Benjamin. In: WISMANN, H. (Ed.). Walter Benjamin et Paris. Colloque International 27-29/Juin/1983. Paris: Editions du Cerf, 1986. p. 529-558.

PELLOUTIER, Fernand. La Grève générale (historique). Disponible < http://www. pelloutier.net/dossiers/dossiers.php?id_dossier=66 >. Consultado el 08/08/2014. Publicado el 06/07/2005.

RAULET, Gérard. Le Caractère destructeur. Paris: Aubier, 1997.

SALZANI, Carlo. Violence as pure praxis: Benjamin and Sorel on strike, myth and ethics. In: COLLOQUY TEXT THEORY CRITIQUE, 16. Actas... Monash University, 2008. p. $18-48$. 
SOREL, Georges. Reflexiones sobre la violencia. Trad. de Luis Alberto Ruiz. Buenos Aires: La Pleyade, 1973. . Matériaux d'une théorie du prolétariat. Genève, Paris: Slatkine, 1981.

STEINER, Uwe. Walter Benjamin. Stuttgart-Weimar: J. B. Metzer, 2004.

UNGER, Erich. Politik und Metaphysik. Würzburg: Königshausen und Neumann, 1989.

\section{Bibliografía COMPLEMENTARIA}

BENJAMIN, Walter. Discursos Interrumpidos I: Filosofía del arte y de la historia. Trad. de Jesús Aguirre. Buenos Aires: Taurus, 1989.

- Sobre el programa de la filosofía venidera. In: . Para una crítica de la violencia y otros ensayos: Iluminaciones IV. Trad. de Roberto Blatt. Madrid: Taurus, 1998. CHUECA, Miguel (ed.). Déposséder les possédants: la grève générale aux «temps héroïques» du syndicalisme révolutionnaire (1895-1906). Marseille: Agone, 2008.

GOURGOURIS, Stathis. The Concept of the mythical (Schmitt with Sorel). Cardozo Law Review, n. 21, p. 1487-1514, 1999-2000.

HAMACHER, Werner. Afformative strike. Cardozo Law Review, v. 13, n. 4, p. 1133-1157, Diciembre, 1991.

PÉREZ LÓPEZ, Carlos. La grève générale comme problème philosophique: Walter Benjamin et Georges Sorel. 2012. 365 p. Tesis (Doctorado en Filosofía) - Laboratoire d'études et de recherches sur les Logiques Contemporaines de la Philosophie, Université de Paris 8, Paris, 2012.

La idea de mito de Georges Sorel en El Capital de Karl Marx. Actuel Marx/ Intervenciones, n. 15, segundo semestre, 2013. ISSN: 0718-0179

PERROT, Michelle. La Jeunesse de la grève. France 1871 - 1890. Paris: Seuil, 1984.

SAND, Shlomo. L'Illusion du politique: Georges Sorel et le débat intellectuel 1900. Paris: Editions La découverte, 1985.

SCHOLEM, Gershom. Walter Benjamin. Histoire d'une amitié. Paris: Calmann-Lévy, 1981. ${ }^{12}$

Recebido em: 05/11/14

Aceito em: 07/01/15 